\section{A 49-year-old with chest pain and collapse}

\section{CLINICAL INTRODUCTION}

A 49-year-old man presented to the emergency department following sudden onset chest pain with collapse. He was refurbishing his home when he collapsed on the floor with chest and abdominal pain. He awoke 1 hour later and called the emergency services due to persisting chest discomfort that worsened with inspiration. On arrival in the emergency department, his pulse was thready $(88 / 58 \mathrm{~mm} \mathrm{Hg})$ with pulsus paradoxus on inspiration. High-sensitivity troponin I was elevated at $325 \mathrm{ng} / \mathrm{L}$ (normal range 1-34 ng/L). Fluid resuscitation was administered and contrast-enhanced CT imaging was performed (figure 1).

\section{QUESTION}

Which of the following best explains this presentation?
A. Type A aortic intramural haematoma
B. Left ventricular diverticulum rupture
C. Malignant pericardial effusion
D. Left ventricular pseudoaneurysm
E. Blunt cardiac trauma

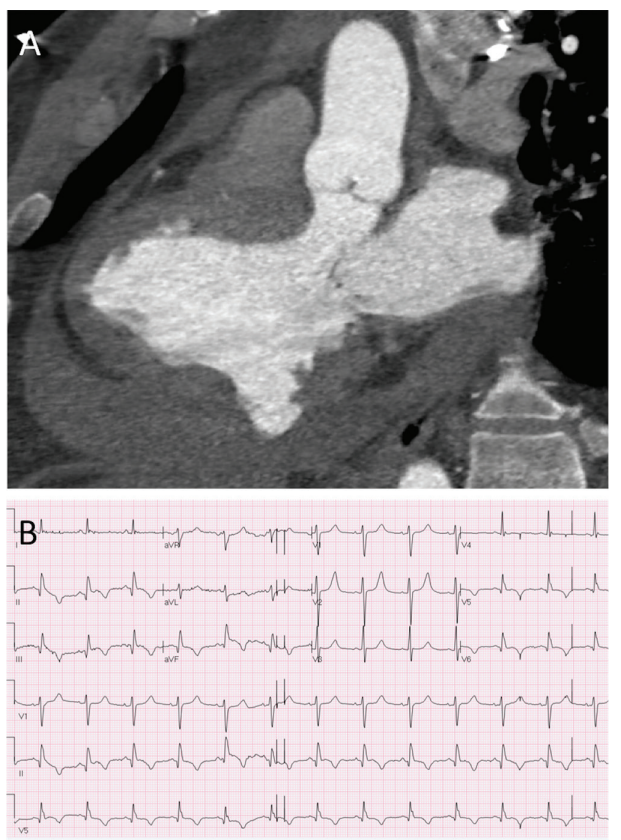

Figure 1 (A) CT angiogram with multiplanar reconstructions in threechamber and axial views. (B) 12-lead ECG.

For the answer see page 968 


\section{A 49-year-old with chest pain and collapse}

For the question see page 930

\section{ANSWER: D}

The correct answer is left ventricular pseudoaneurysm. CT angiography demonstrates a large pericardial effusion with superior extension into the aortic and pulmonary recesses. The pericardium is not calcified and the pericardial fluid has a CT number of 43 Hounsfield units that suggests recent blood accumulation. There is discontinuity of the inferolateral wall with a filling defect containing iodinated contrast and no extravasation into the pericardial space. This is a contained rupture of the inferolateral left ventricular wall with thrombus formation preventing catastrophic exsanguination.

There is no intimal flap or aortic wall haematoma to indicate acute aortic syndrome. Left ventricular diverticula are outpouchings of myocardium usually found at the apex, which in combination with diaphragmatic and sternal defects constitute Cantrell's syndrome. ${ }^{1}$ Blunt cardiac trauma often involves the right heart chambers due to their close proximity to the sternum in conjunction with deceleration injuries involving the great vessels. $^{2}$ Malignant effusions are often blood-stained, but not associated with myocardial wall rupture.

Surgical evacuation and patching of the pseudoaneurysm was performed to relieve cardiac tamponade (see Figure 2 and online supplementary movie). The infarcted tissue was mature with macroscopic scarring. Contained rupture is rare following myocardial infarction and confers a poor prognosis $(75 \%$ inhospital mortality). ${ }^{3}$ It is typically a late complication of myocardial infarction, diagnosed within 6 months following episodes of recurrent chest pain. Inferolateral pseudoaneurysms are more frequently contained by pericardial adhesions, thus preventing rapid deterioration. ${ }^{4}$ The patient recollected an episode of
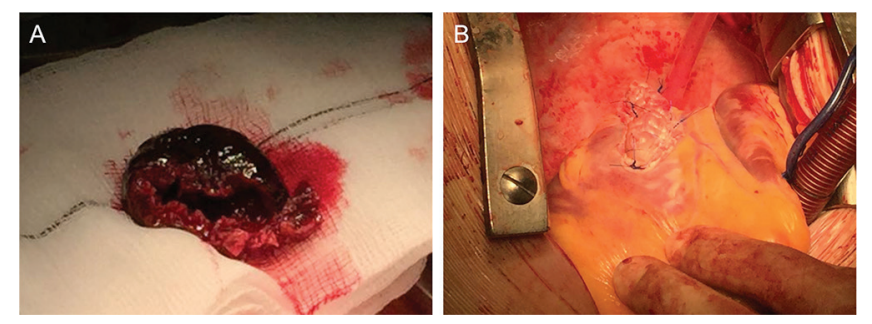

Figure 2 Wide-necked inferolateral wall left ventricular pseudoaneurysm and thrombus resection $(A)$ and repair at the site of mature scar formation (B). ischaemic-sounding chest pain 8 months ago, for which he did not seek medical attention (see online supplementary figure). Left ventricular pseudoaneurysm formation was a complication of transmural infarction due to right coronary artery occlusion.

Alastair J Moss, ${ }^{1}$ Kelvin HH Lim, ${ }^{2}$ Alan G Japp ${ }^{2}$

${ }^{1}$ Centre for Cardiovascular Science, University of Edinburgh, Edinburgh, UK

${ }^{2}$ Department of Cardiothoracic Surgery, Royal Infirmary of Edinburgh, Edinburgh, UK

Correspondence to Alastair J Moss, Centre for Cardiovascular Science, University of Edinburgh, Chancellor's Building, Royal Infirmary of Edinburgh, 51 Little France Crescent, Edinburgh EH16 4TJ, UK; alastairmoss@gmail.com

Acknowledgements The authors thank Dr Sowmya Venkatasubramanian, Edinburgh Heart Centre at the Royal Infirmary of Edinburgh, for her assistance in providing transthoracic echocardiography images.

Competing interests None declared.

Provenance and peer review Not commissioned; externally peer reviewed.

\section{(6) \\ OPEN ACCESS}

Open Access This is an Open Access article distributed in accordance with the terms of the Creative Commons Attribution (CC BY 4.0) license, which permits others to distribute, remix, adapt and build upon this work, for commercial use, provided the original work is properly cited. See: http://creativecommons.org/licenses/by/4.0/

- Additional material is published online only. To view please visit the journal online (http://dx.doi.org/10.1136/heartjnl-2016-310923).

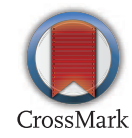

To cite Moss AJ, Lim KHH, Japp AG. Heart 2017;103:968.

Received 16 November 2016

Revised 20 December 2016

Accepted 27 December 2016

Published Online First 10 February 2017

Heart 2017;103:968. doi:10.1136/heartjnl-2016-310923

(c) Article author(s) (or their employer(s) unless otherwise stated in the text of the article) 2017. All rights reserved. No commercial use is permitted unless otherwise expressly granted.

\section{REFERENCES}

1 Cantrell JR, Haller JA, Ravitch MM. A syndrome of congenital defects involving the abdominal wall, sternum, diaphragm, pericardium, and heart. Surg Gynecol Obstet 1958; 107:602-14.

2 Leavitt BJ, Meyer JA, Morton JR, et al. Survival following nonpenetrating traumatic rupture of cardiac chambers. Ann Thorac Surg 1987;44:532-5.

3 Figueras J, Alcalde O, Barrabés JA, et al. Changes in hospital mortality rates in 425 patients with acute ST-elevation myocardial infarction and cardiac rupture over a 30-year period. Circulation 2008;118:2783-9.

4 Figueras J, Cortadellas J, Evangelista A, et al. Medical management of selected patients with left ventricular free wall rupture during acute myocardial infarction. J Am Coll Cardiol 1997;29:512-8. 